\title{
COMPORTAMENTOS COMUNICATIVOS DO BEBÊ COMO PARCEIRO ATIVO NA INTERAÇÃO*
}

\author{
COMMUNICATIVE BEHAVIOURS OF THE BABY AS AN \\ ACTIVE PARTNER IN THE INTERACTION
}

Neusa Guaraciaba dos Santos de Oliveira ${ }^{1}$ Vera Silvia Raad Bussab ${ }^{2}$

SANTOS-OLIVEIRA, N. G.; BUSSAB, V. S. R. Comportamentos Comunicativos do Bebê como Parceiro Ativo na Interacão, Rev. Bras. Cresc. Desenv. Hum., São Paulo, 6 (1/2), 1996.

Resumo: As autoras apresentam uma visão do bebe, que desde o nascimento é dotado de capacidades para se comunicar com quem Ihe presta cuidados. Tendo como referencial a teoria do Apego de Bowlby, elencam alguns trabalhos que demonstram os comportamentos comunicativos do bebe que os torna um parceiro ativo na intera,cão. Partindo deste enfoque, as autoras sugerem uma nova forma de prestar cuidados, qual seja, através da comunicação, considerando e respeitando os sinais emitidos pelo bebe.

Palavras-clave: apego, desenvolvimento, interacão adulto-bebê, cuidados infantis.

Nos últimos quinze anos, muitos trabalhos sobre as capacidades do bebê indicam uma revolucão no conceito que se tinha a seu respeito. Hoje o bebê não é mais visto como uma massa sem formas, prestes a ser modelada pelo seu meio ambiente: pois demonstrou-se que ele, desde o nascimento, apresenta predisposição para estabelecer formas elementares de interação social. Segundo BUSSAB (1989) “ ... passaram de criaturas passivas para ativas; demonstraram possuir capacidades perceptuais e sociais mais precoces do que se imaginava; apresentaram-se como reguladores recíprocos no contato com o adulto e como tendo preferências típicas.” (p. 183).

Vários autores, como por exemplo PAPOUSEK \& PAPOUSEK (1984); TREVARTHEN (1984) e BUSSAB \& PAVONE (1986), demonstraram que os bebês humanos nascem com padrões comportarnentais que os deixam prontos para interagirem com os adultos que os circundam, que por sua vez, demonstram capacidades inconscientes de ajustamento. Com efeito estes estudos demonstraram que as interações que se estabelecem entre os bebês e os adultos requerem trocas ajustadas, respeito aos sinais emitidos pelos parceiros, sugerindo até a existência de regras na comunicação. "Estas experiências precoces cotidianas parecem ser fundamentais para o desenvolvimento integrado da criança. Há evidências de que a intencionalidade, a autoconsciência e as noções de causalidade desenvolvam-se através dessa experiência e da integração do desenvolvimento afetivo e cognitivo." (BUSSAB, 1989, p. 186).

Segundo BRAZELTON (1987) “O bebê é visto como um ser complexo e previsível, que interage com os adultos que o cercam. Ele os modela quase tanto quanto é influenciado por eles.” (p. 9). Este autor prossegue considerando que, diante desta nova visão do bebê, o início do

\footnotetext{
* Parte da introdução da dissertação de mestrado defendida em Junho de 1996. no instituto de Psicologia/USP, sob o titulo “Amamentação em creche no local de trabalho da mãe”. Orientadora: Profa. Dra. Vera Silvia Raad Bussab. Financiada pela CAPES e CNPq.

1 Psicóloga, Pesquisadora do CDH, Mestre em Psicologia Experimental e Doutoranda em Psicologia Experimental/USP. End. Av. Dr. Arnaldo, 715 sala21. subsolo, CEP: 01246-904. SP - Fone/Fax (011) 3061-3572.

2 Profa. Dra. do Departamento de Psicologia Experimental - Instituto de Psicologia da Universidade de São Paulo. Pesquisadora do CNPq. End: Av. Prof. Mello Moraes. 1721. São Paulo - SP, CEP 05508-900 CX: 66.261 - Fone: (011) 808-4001.
} 
desenvolvimento emocional, cognitivo, afetivo e social deve ser reconceitualizado, sendo que suas capacidades são uma evidência dos precursores do ego. Tais capacidades são observáveis pelos pais, podendo servir de base à função parental. Esta torna-se assim uma interação com o bebê, que por sua vez toma o papel de um participante ativo e suficientemente previsível.

As capacidades do bebê para prestar atenção e interagir com o parceiro adulto sensível às suas necessidades levaram Brazelton a considerar a dependência deste ao meio maternal sob um novo ângulo. Afirma o autor: "Nós não mais podemos considerar o recém-nascido como insensível, caótico ou imprevisível; nós o vemos de preferência como estando equipado com reações altamente previsíveis a todos os estímulos vindos do exterior, quer estes estímulos sejam positivos (portanto apropriados ao sujeito) ou negativos (e portanto impróprios ou excessivos). Nossa hipótese será que as reações dos recém-nascidos podem modelar as respostas do adulto por constituírem um sistema de 'feed back' mútuo. Doravante, natureza e ação maternal tornam-se inseparáveis e entrelaçadas, tendo em vista a necessidade de 'feed back' recíproca, própria dos dois participantes da díade.” (ib. p. 13).

BOWLBY (1984), em sua teoria sobre o apego, coloca que o bebê nasce com as bases do comportamento social, sendo que o apego se desenvolve depois de um certo tempo na interação com a mãe ou pessoa que lhe presta cuidados.

O comportamento de apego “é qualquer forma de comportamento que resulta em uma pessoa alcançar e manter proximidade com algum outro indivíduo claramente identificado, considerado mais apto para lidar com o mundo.” (BOWLBY, 1989, p.38-39.) Neste sentido, o fato de uma figura de apego estar disponível, ou seja, dar respostas adequadas às necessidades do outro, estabelece um clima de segurança e conseqüentemente de bem-estar.

Embora o comportamento de apego seja mais evidente na infância, o mesmo pode ser observado durante todas as etapas do desenvolvimento do ser humano: infância, adolescência e fase adulta. Nestas fases, o comportamento de apego torna-se explícito nas situações de ameaça interna, quando a atenção e os cuidados do outro dão segurança, diminuindo o sofrimento do indivíduo.

O apego é estabelecido na relação da criança com a pessoa que lhe presta cuidados. Há uma relação direta entre a forma como estes cuidados são prestados e o tipo de apego desenvolvido, conforme vem sendo demonstrado por inúmeras investigações.
AINSWORTH et al. (1978), através de um estudo experimental quando testaram a reação de crianças à separação de suas mães, identificaram três tipos de apego: apego seguro, apego ansiosoambivalente e o apego evitativo. O apego seguro é caracterizado por um vínculo de segurança, ou seja, a criança confia na disponibilidade de seus pais (ou substitutos) em apoiá-la caso se encontre em situações ameaçadoras, podendo assim explorar o mundo. Este tipo de apego é estimulado por um dos pais, especialmente a mãe, nos primeiros anos quando está imediatamente disponível, sensível aos sinais da criança e com respostas amáveis, sempre que esta procura proteção e/ou conforto.

$\mathrm{O}$ apego ansioso-ambivalente desenvolvese quando a criança não tem certeza se seus pais estarão disponíveis para apoiá-la quando necessitar. Neste caso, as respostas das mães aos sinais da criança são ambivalentes: ora a mãe mostra-se disponível ora não. Segundo este modelo, a criança sente-se desprotegida não tendo segurança para explorar o mundo, reagindo negativamente à separação da mãe, necessitando sempre tê-la por perto mostrando agarramento a esta.

O apego evitativo é resultante de uma relação onde a criança não recebe respostas dos pais quando necessita de ajuda, estas mães caracterizam-se por serem rejeitadoras ou intrusivas, não reagindo, em ambos os casos, aos sinais da criança. Estas crianças apresentam comportamentos evitativos de contatos físico e afetivo, que parecem ser defesas à rejeição vivenciada.

Estes modelos de apego podem apresentar um valor preditivo uma vez que, através da observação da relação mãe-criança, é possível prognosticar futuros problemas no desenvolvimento baseando-se no tipo de comportamento da mãe. Uma mãe sensível aos sinais do bebê, que responde de forma contingente, estará promovendo o desenvolvimento harmonioso da criança.

Os comportamentos que compõem o apego, segundo AINSWORTH (1969) e BOWLBY (1984), constituem um certo número de padrões tais como: orientação visual e postural, movimento de busca do mamilo e sucção, choro na separação e cessação do choro no retorno, sorriso, vocalizações, segurar e alcançar, ansiedade de separação, aproximação, acompanhamento, encontro, subir e explorar, esconder o rosto, usar a mãe como base para exploração, fugir para a mãe e agarrar. O apego caracteriza-se quando a criança dirige estes comportamentos com maior freqüência a uma pessoa, em geral a mãe, do que às demais.

Durante muito tempo postulou-se que a criança vinculava-se à mãe por esta fornecer o alimento. Neste sentido. dois tipos de impulsos estariam presentes: um primário, que é a satisfa- 
ção causada pelo fomecimento do alimento e outro secundário, que é a relação pessoal que se estabelece nessa situação.

BOWLBY (1984) reuniu evidências de que o fornecimento de leite em si não é condição suficiente para gerar o vínculo de apego. Diversos estudos arrolados por ele mostram que as crianças tendem a se vincular às pessoas que consistentemente interagem de modo afetivo com elas, respondendo às suas iniciativas ou iniciando interações lúdicas adequadas. Estes são os fatores essenciais para o desenvolvimento do apego e não a satisfação de outras necessidades primárias. Prova disso está no fato de ser possível o estabelecimento do vínculo com pessoas que não participam em nenhum grau dos cuidados físicos da criança.

Baseando-se nos estudos de Lorenz que demonstrou que gatinhos e gansinhos apegavamse à figura materna sem que esta os alimentasse e nos estudos de Harlow, Bowlby conceituou o comportamento de apego, "como uma classe especial de comportamento com dinâmica distinta do comportamento de alimentação ou sexo, duas fontes de motivação humana ha muito consideradas como as fundamentais.” (BOWLBY, 1989, p. 38).

Assim, para este autor, o apego pertence a uma classe especial de comportamento, tendo uma motivação intema própna distinguindo-se da alimentação e do sexo, e de igual importância para a sobrevivência.

Bowlby, em sua teoria, diferencia apego de comportamento de apego. O primeiro é um vínculo afetivo que liga a criança a alguém e que esta "está fortemente disposta a procurar proximidade e contato com esse alguém e a fazê-lo, principahnente, em certas condições especiíficas." (ib. p.40). Já o comportamento de apego refere “as várias formas de comportamentos nas quais a pessoa se engaja de tempos em tempos para obter ou manter uma proximidade desejada.” (ib. p. 40). Assim, a diferença marcante entre os dois conceitos diz respeito à sua natureza e durabilidade. $\mathrm{O}$ apego é dirigido à pessoas específicas, sendo um vínculo duradouro e o comportamento de apego pode ser eliciado em determinadas circunstâncias e dirigido a várias pessoas, embora, é claro, haja forte correlação entre o vínculo e o comportamento.

A existência de predisposições naturais nas crianças e nos adultos para o desenvolvimento do vínculo, além do fato de que este se estabelece por vias específicas e não necessariamente ligadas à satisfação de outras necessidades básicas sugere, segundo Bowlby, que o sistema de apego é em si primário, foi selecionado, é adaptativo, faz parte da natureza humana e de suas necessi- dades básicas. Na criança, o apego torna-se explícito através dos comportamentos já citados, enquanto no adulto uma de suas manifestações é através da necessidade de prestar cuidados a quem necessita.

A teoria de Bowlby sobre o apego motivou uma série de pesquisas que demonstram as capacidades dos bebês humanos ligadas à comunicação. Dentro de um nível de organização próprio, o bebê está equipado para interagir com os adultos cuidadores, ou seja, com quem lhe presta cuidados. Neste sentido, saber interpretar os sinais do bebê toma-se fundamental, para que os cuidados tenham a função de promover um desenvolvimento adequado e hannonioso do bebê.

Considerando-se o momento histórico atual, quando a mulher-profissional está cada vez mais dispulando o mercado de trabalho e, conseqüentemente, necessita dividir e complementar o seu papel de mãe com outras pessoas, esta visão de prestar cuidados como uma forma de interação torna-se fundamental. Assim, cuidar do bebê deixa de ser um ato mecânico e técnico, tornando-se em uma forma de comunicação.

É interessante, portanto, levantar alguns estudos sobre os comportamentos do bebê ligados à comunicação.

Segundo CARPENTER (1974), a criança de duas semanas de vida apresenta comportamentos de maior atenção pelo rosto de sua mãe do que pelo de uma pessoa estranha. Através de um experimento o autor conclui que quanto mais a mãe fala com seu bebê, mais essa atenção é desenvolvida, sendo que uma atenção maior é dada ao rosto da mãe quando este é acompanhado da voz do que quando não o é. Contudo, quando os estímulos rosto e voz são apresentados de um forma descoordenada o bebê desvia a cabeça, deixando de prestar atenção à sua inãe.

FANTZ (1963) já havia demonstrado, anteriormente, a preferência visual do recém-nascido por estímulos com características similares às do semblante humano. GOREN et al. (1975) confirmam este estudo do ponto de vista da orientação: o bebê dirige-se mais distintamente para a figura de um rosto humano do que para uma figura que imita o rosto humano e que tem os traços faciais especialmente desordenados.

Interessando-se pelas expressões vocais dos bebês como choro, vocalizações, bem como pelas trocas posturais entre a mãe e o bebê, WIDNER \& TISSOT (1987) realizaram um estudo longitudinal em 12 bebês durante os 6 primeiros meses de vida. Os autores demonstraram como os bebês, nas primeiras semanas de vida, reagem posturalmente de modo diferente à mãe e a uma pessoa estranha, sendo que, com esta última, os 
bebês apresentaram um controle da distância corporal logo que eram pegos no colo.

SCHALL et al. (1980) bem como MONTAGNER (1982) colocam em evidência a capacidade do recém-nascido em distinguir sua mãe de uma estranha pelo odor. Reciprocamente, a mãe seria capaz de reconhecer o odor corporal de seu filho a partir do $3^{\circ}$ dia de vida.

Do ponto de vista da comunicação, é interessante notar que o sistema auditivo do bebê parece pré-adaptado para tratar as frequiências típicas da linguagem humana. Os recém-nascidos preferem a voz humana a sons produzidos por objetos e as vozes femininas às masculinas (KLAUS \& KLAUS, 1989).

Ainda dentro deste mesmo enfoque, alguns trabalhos analisaram o sistema de comunicação existente entre a mãe (ou adulto) e o recém-nascido. A sincronia temporal refere-se à coordenação de movimentos entre indivíduos em interações sociais: existe uma tendência entre os indivíduos a se moverem no ritmo da fala do parceiro e isto parece representar uma característica fundamental do comportamento interativo para o desenvolvimento de uma comunicação satisfatória. CHAPPELL \& SANDER (1979) salientam que a sincronia está na base da aquisição da significação, pois é necessário que um acordo mútuo seja estabelecido para que a significação emerja, para que a troca exista. CONDON \& SANDER (1974) mostraram que tal sincronia estabelece-se desde as primeiras semanas de vida: o bebê é capaz de mover-se em concordância temporal com o ritmo do discurso que ouve. Mais precisamente, ele se move quando os sons se modificam e mantém uma postura determinada durante o período de produção de um som.

Se, por uin lado, o bebê é capaz de ajustar seus ritmos aos da mãe. por outro, a mãe apresenta ritmos coerentes e coordenados no conjunto de sua atividade quando interage com a criança. Uma mãe sensível procura regular seu comportamento de forma que este esteja em harmonia com o de seu bebê. Para que isso ocorra, a mãe tem que respei- tar o ritmo das interações e interrupções do bebê.

As comunicações não-verbais entre a mãe e a criança fornecem ao bebê a oportunidade de dominar os aspectos estruturais da situação de diálogo. BATESON (1979) descreve as "proto-conversações” nas quais se engajam a mãe e a criança, como modelos de vocalizações mais ou menos alternados que apresentam muito mais períodos de vocalizações não-encontrados do que simultâneos, típicos de situação de diálogo.

Segundo OSOFSKY (1976), num diálogo, cada um dos interlocutores é ativo e influencia o outro. Estudando pares mães-bebês, entre dois e quatro dias de vida, observou correlações entre os comportamentos da mãe e os da criança, no momento da alimentação. Se, neste momento, a mãe conversava com alguém, o bebê parava de sugar ou alterava seu ritmo de sucção, prestando atenção na mãe.

ROBIN (1982) analisou a adaptação progressiva das posturas da mãe e dos comportamentos do bebê no período do aleitamento. A criança age tanto sobre sua mãe, através de seus olhares, sorrisos, mímicas, quanto a mãe sobre o seu bebê por meio de palavras, gestos e toques que possuem um efeito tranqüilizador.

O conjunto das pesquisas examinadas até aqui tende a mostrar a presença, desde o nascimento, de modelos comportamentais pré-adaptados à instauração de um sistema de comunicação equilibrado entre a mãe e a criança. Os comportamentos organizados do bebê orientam e facilitam a intervenção da mãe sobre ele, facilitando a formação do vínculo, que vai se solidificando no desenrolar da interação.

Embora a maioria dos estudos nessa área enfatizem a figura da mãe como a responsável pelos cuidados prestados ao bebê, vale a pena esclarecer que outras figuras que complementam estas funções também podem desenvolver estas habilidades, estabelecendo com ele interações harmoniosas e equilibradas propiciando um ambiente favorável à promoção de um desenvolvimento integral.

\begin{abstract}
The authors present an image ofthe baby, who, since its birth, is capable of communicating with whom takes care of it. Based in Bowlby's theory of Attachment, this paper shows some studies that demonstrate the communicative behaviours which make the baby be an active partner in the interaction. In the light of this, the authors suggest a new way of rendering care: through communication, considering and respecting the signs emitted by the baby.
\end{abstract}

Key-words: attachment, development, adult-baby interaction, child care. 


\section{REFERÊNCIAS BIBLIOGRÁFICAS}

AINSWORTH, M. D. S.; WALTERS, M. C.; SWALL, E. S. Patterns of attachment: a psychological study of the strangesituation. N. S. E. Hilsdale, 1978..

AINSWORTH, M. D. S. Object relations, dependency and attachment: a theoretical review of the infant-mother relationship. Child Dev., 40: 969- 1025,1969.

BATESON, M. C. The epigenesis of conversational interction: a personal account of research development. In: BULLOWA, M. (ed) Before speech. The heginning of interpersonal communication, p. 63-77, University Press, Cambridge, 1979. Paulo, 1984

BOWLBY, J. Apego. Martins Fontes, São

BOWLBY, J. Uma base segura. Aplicações clínicas da teoria do apego. Porto Alegre, Artes Médicas, 1989.

BRAZELTON, T. B.; CRAMER, B. G. As primeiras relações. São Paulo, Martins Fontes, 1992.

BRAZELTON, T. B. O bebê: parceiro na interação. In: BRAZELTON, T.B.; CRAMER, B.; KREISLER, L.; SCHAPPI, R.; SOULÉ, M. P. A dinâmica do bebê. Porto Alegre, Artes Médicas, 1987. p.9-23.

BUSSAB, V. S. R. Comportamento humano. Origens evolutivas. In: ADES, C. org. Etiologia de animais e de homens. SãoPaulo, Edicon/ Edusp, 1989. p. 173-188.

BUSSAB, V. S. R.; PAVONE, S. A comunicação pré-verbal: um estudo exploratório. Anais da 38 ${ }^{a}$ Reunião Anual da S.B.P.C. 1986.p. 1052.

CARPENTER, G. Mother's face and the newborn. New Scientist, 21: 742-744, 1974.

CHAPPELL, P. F.; SANDER, L. W. Mutual regulation of the neonatal-maternal interaction process: context for the epigenesis of communication. In: BOLLOWA, M. ed. Before speech. The heginning of interpersonal communication. Cambridge, University Press, 1979. p. 89-108.

CONDON, W. S.; SANDER, L.W. Neonate movement is synchronized with adult speech: interactional participation and language acquisition. Science, 183: 99-101, 1974.
FANTZ, R. Pattern vision in newborn infants. Science, 40: 296-297, 1963.

GOREN, C. C.; SARTY, M.; PAUL, Y. K.; WU, M. B. Visual following and pattern discrimination of face-like stimul by newborn infants. Pediatrics, 56 (4): 544-549, 1975.

KLAUS, M. H.; KENNELL, J. H. Pais/ Bebê a formação dc apego. Porto Alegre, Artes Médicas, 1993.

KLAUS, M.; KLAUS, P. O surpreendente recém-nascido. Porto Alegre, Artes Médicas, 1989.

MONTAGNER, H. Données nouvelles sur la gernèse des systèmes d'interaction chez des enfants de moins de 2 ans. Bull.Audiophonol., (23): 162-184, 1982.

OSOFSKY, J. D. Neonatal characteristics and mother-infant interaction in two observacional situations. Child Dev., 47: 1138-1147, 1976.

PAPOUSEK, H.; PAPOUSEK, $M$. Learning and cognition in the every day life of human infants. Adv. stud. hehav., 14: 127-163, 1984.

ROBIN, M. Interaction process analyses of mothers with their newborn infants. Early Child Dev. Care, 6: 93-108, 1982.

SANTOS-OLIVEIRA, N. G. Amamentação em creche no local de trabalho da mãe. São Paulo, 1996. [Dissertação de Mestrado - Instituto de Psicologia da USP].

SCHALL，B.; MONTAGNER, H.; HERTLING, E.; BOLZONI, D.; MOYSE, A.; QUICHON, R. Les stimulations olfactives dans les relations entre l'enfant et la mère. Reprod. Nutr Dev., 20: 843-858, 1980.

TREVARTHEN, C. Emotions in infancy: Regulations of contact and relationships with persons. In: SHERER, K.R.; EKMAN, P. orgs. Approaches to emotions. London, New York, LEA, 1984.

WIDNER, C.; TISSOT, R. Les modes de communication du bébé-postures, moviments et vocalises. Paris, Dlachaux et Niestlé, 1987.

Recebido em: 01/11/96 Aprovado em: 01/12/96 